\title{
THE BRaIN, Home OF THE GODS
}

\section{Karlijn Massar}

Dept. Work \& Social Psychology, Faculty of Psychology \& Neuroscience, Maastricht University, The Netherlands

Karlijn.massar@maastrichtuniversity.nl

A Review of the Book

\section{Evolving Brains, Emerging Gods. Early Humans and the Origins of Religion}

By E. Fuller Torrey. 2017.

Columbia University Press, New York, NY, USA, 291 pages.

ISBN 9780231183369 (Hardback, US\$35.00)

Most of the major religions in the world teach their followers that god(s) created man. An evolutionary neuroscientific approach to religion however suggests a reversed causal relationship: our brains created the gods. Darwin, in the Descent of Man, already posited that religion and spirituality might be the product of our brain organization, and that man thus created god(s). Indeed, he stated that religious beliefs might only develop after a ' $[\ldots]$ considerable advance in the reasoning powers of man, and from a still greater advance in his faculties of imagination, curiosity, and wonder' (1871, p.395). In Evolving Brains, Emerging Gods, E. Fuller Torrey carefully extends this argument, and shows how the emergence of spiritual and religious beliefs coincides with - or rather, follows from brain evolution and cognitive developments.

Rather than providing an answer to why humans have created gods and other deities, Torrey describes how humans were able to do so, over the course of two million years. To support his arguments, he describes converging evidence from archaeology, ontogeny, phylogeny, and (evolutionary) neuroscience, and he does so using terms and language that those not familiar with neuroscience can easily follow. Central to many of the 
arguments and evidence he presents - especially in the second part of the book - is the concept of parallel evolution: The evolutionary process where organisms who have a common genetic origin continue to evolve along similar lines - even though they have been separated from one another for thousands of years. Similar to agriculture, the gods (and religions) emerged more or less simultaneously on different continents, starting between 11.000 and 7.000 years ago. Torrey argues that this is likely the result of brain developments that took place before Homo sapiens dispersed outside Africa.

The book has two parts: Part 1 - the Making of the Gods - comprises the largest part of the book, and tracks brain and cognitive evolution from Homo habilis to (early) Homo sapiens. The chapters in this part have a similar structure, starting with the daily lives and practices of these hominin, delving into the cognitive development that characterizes them - respectively: intelligence, awareness, empathy, introspection, and temporal cognition - and ending with a summary of archaeological and neuroscientific evidence of evolved brain structures. Part 2 - the Emergence of the Gods - starts with the agricultural revolution, and traces the development of belief, worship, and religions across the world and through to modern times. This part takes us from rudimental ancestor worship among Homo sapiens to the major religions still existing today, and ends with a summary of other theories on the origins of gods. I will briefly summarize these parts below.

\section{Part 1: The making of the gods}

The first part of the book focuses on the five major cognitive advances that allowed early humans to cognitively create the first gods. Homo habilis, around 2 million years ago, was considerably smarter than any preceding hominin, and archeological findings show this was due to an increase in the frontal-posterial (parietal) network encompassing among others the frontal pole and prefrontal cortex. Even more 'human' was Homo erectus (1.8 million years ago): this hominin showed remarkable developments in tool-making and social relationships, and it had the capacity to recognize itself. This self-awareness was the result of brain evolution involving in particular the insula, the inferior parietal, and the anterior cingulate, as well as an increase in complexity in the white matter connecting tracts. Then, some 230.000 years ago, Neanderthals and other archaic Homo sapiens emerged, and with it, empathy. Torrey argues that the existence of Neanderthal burial sites implies that these humans cared for each other, and thus may have experienced empathy. Empathy in turn requires the ability to have a sense of what the other person is thinking, feeling, or experiencing, i.e., to have a theory of mind (ToM). Theory of mind is thought to involve the right temporo-parietal junction (RTPJ) as well as the anterior cingulate, insula, and medial prefrontal cortex. Archeological evidence shows that archaic Homo sapiens had a larger brain case, and an expanded parietal lobe.

However, even though Neanderthals might have had a rudimentary theory of mind, which is generally accepted as a prerequisite for a belief in gods (see e.g. Bering, 2011), Torrey argues that they were likely not able to think about the mind of a god, and how this god was thinking about them, since they also were not able to 'think about thinking' yet (second-order ToM). Moreover, judging from archeological evidence from skulls, Neanderthals likely were not able to think about the past or the future. These abilities seemed to emerge when early Homo sapiens, around 100.000 to 60.000 years ago, gradually left Africa and dispersed across the globe. Evidence from caves and rock 
shelters in the Middle East and South Africa suggests these hominins possessed highly advanced tool-making skills, and adopted frequent use of clothing and self-decoration. According to Torrey, these skills, in addition to the use of boats to travel across open oceans, were indications of an ability to plan ahead and prepare accordingly. Importantly, early Homo sapiens also possessed the ability to contemplate themselves: Consciousness, or introspection, had evolved. Interestingly, the brain areas that are associated with these abilities overlap with the brain areas that are associated with the development of language. In its essence then, Torrey views religion and belief as an extension of our social selves.

Torrey firmly places the cognitive capacity for the creation of the gods with modern Homo sapiens, around 40.000 years ago, around which time migration out of Africa took place and technological innovation, self-ornamentation, and the advent of the arts developed in rapid succession. Around 12.000-11.000 years ago, when humans transitioned from hunter-gatherers to being settled farmers, archaeological evidence of grave goods in burial sites also appeared. Torrey views such grave goods as evidence that modern Homo sapiens now developed autobiographical memory and had the capacity to think about the self in the past and the future, with the associated belief that humans continue to live on after their bodies die.

\section{Part 2: The emergence of the gods}

In this part, Torrey details how a gradual warming of the earth caused the conditions that facilitated the development of agriculture and the domestication of animals, and larger gatherings of groups of humans. Such a sedentary lifestyle, he argues, is key to the worship of ancestors, because it allows for the dead to be buried. There is evidence that as plants and animals became domesticated, ancestors became more prominent in humans' lives as well. During the early agricultural revolution, the dead were kept very close to home (often buried underneath houses). In some areas, 'skull cults' arose, with skulls of the deceased placed on clay altars in the home, sometimes plastered and painted. The continued development of the lateral prefrontal cortex, and the superior longitudinal fasciculus (a tract of white matter connecting the prefrontal cortex to the parietal and temporal lobes) is considered to be crucial to this co-evolution of agriculture and ancestor worship.

But when did the first 'gods' appear, and how were ancestral spirits transformed into deities? Torrey argues that two things needed to happen before gods could make an entrance. First, some ancestral spirits needed to become very powerful - e.g., an ancestral spirit providing good crops for a few years in a row - and second, there needed to be a critical mass of humans. These groups needed to establish amongst themselves which of their spirits was the most powerful, and out of this hierarchy of spirits, the first gods emerged (i.e., the highest ranking spirits). Since the emergence of the gods can only be established precisely when humans invented writing - around 6.500 years ago, in Mesopotamia - the rough estimate is that they emerged around that time or slightly earlier. In the 2.500 years following, as societies became more complex, so did the world of the gods and their responsibilities. For example, gods took on judicial, economic and political responsibilities, and gradually, as empires increased, the gods gained increasing 
power, and had human representatives across the world (e.g., pharaos). By this time 4.500 years ago -Torrey states, humans were truly theistic hominins.

The book ends with a very brief summary of other theories of the origins of the gods, most of which are psychological and are focused on the needs that are satisfied by believing in a higher power - whether this is a single deity or a collection of gods. The figure on page 8.1 nicely summarizes the essence of the book and these other perspectives.

\section{Conclusion}

To sum up, Torrey suggests that the ancestors and the gods provided answers for natural phenomena (e.g., rain, sun, and moon) and philosophical questions (Why am I here? What will happen to me after I die?), and as such were a comforting presence in light of our awareness of our inevitable deaths. Throughout the book, even as he is carefully detailing the neuroscientific and archaeological evidence for the neurological and cognitive developments of hominins, Torrey paints a picture of these individuals' daily lives, and how a belief in deities may have played a (central) role. As I already stated, the book is really engaging and accessible for scientists and non-scientists alike, and is highly recommended for those interested in the intersection between religious studies, psychology, anthropology and neuroscience.

\section{ABOUT THE AUTHOR}

KARLIJN MASSAR is a social and evolutionary psychologist at Maastricht University, The Netherlands. She obtained her $\mathrm{PhD}$ at the University of Groningen, where she studied sex differences and unconscious processes in the evaluation of romantic rivals. Her current research still focuses on jealousy and intrasexual competition, but has also expanded to include health psychology and the role of psychological capital (psycap) in increasing healthy lifestyles among individuals with a lower SEP. Further, she supervises $\mathrm{PhD}$ students across the world (Panama, Nigeria, Sudan, Indonesia, South-Africa) and often utilizes the Intervention Mapping framework in these projects. ORCID: https:// orcid.org/0000-0003-4388-3846

\section{REFERENCES}

Bering, J. (2011). The belief instinct: The psychology of souls, destiny, and the meaning of life. WW Norton \& Company. 